\title{
Diffusion of knowledge in the biotechnology sector
}

\author{
Małgorzata Niklewicz-Pijaczyńska ${ }^{1, *}$ \\ ${ }^{1}$ University of Wroclaw, Faculty of Law, Administration and Economics, pl. Uniwersytecki 1, \\ Wrocław, Poland
}

\begin{abstract}
The aim of the paper is to analyze the use of existing legally protected solutions an. publications made available through patent systems for the development of further biotechnological inventions. For its implementation, was conducted research based on the so-called patent citations of two kinds - to literature and previously published, other patents. For the needs of the paper, technical documentation of 88 patents in the resources of the Polish Patent Office and Espacenet was analyzed. The study includes 40 Polish biotechnology companies with significant innovation activity. The results of the conducted research allow to formulate two conclusions. First, the knowledge obtained from patent resources plays an important role in the innovation process of inventions in the biotechnology sector. Secondly, this knowledge is characterized by a high degree of internationalization, first of all are cited foreign inventions and source literature, domestic citations appear relatively rarely. Among observed references, citing American achievements plays a dominant role - this applies to both literature and inventions, which suggests that the US patent system is the main source of patent knowledge for Polish biotechnology companies.
\end{abstract}

\section{Introduction}

In knowledge-based economy, biotechnology understood as the technological application of biological systems, living organisms and their derivatives to produce new or modified products and processes, it is a branch of industry and at the same time a field of science that sets trends and a direction for the development of the most modern breakthroughs. It is also a branch in which the compatibility of medical, economic and scientific challenges leads to the continual emergence of new solutions. Its achievements often condition and stimulate inventive activity not only in the home area, but also in other industries based on advanced technologies. The Directive of the European Parliament and the Council of 1998 emphasizes the importance of biotechnology, mainly for the development and protection of the environment and health, in particular in the fight against epidemic diseases and insufficient supply of food in developing countries [1]. Biotechnology and genetic engineering is at the same time the branch in which the compatibility of medical, economic

\footnotetext{
* Corresponding author: malgorzata.niklewicz-pijaczynska@uwr.edu.pl
} 
and scientific challenges leads to continually emerging new solutions. The dynamics of creating biotechnological inventions is at the same time an opportunity and a challenge. It requires not only a strong diversification of information sources but also continuous control, continuous acquisition and fast orientation in the sheer volume of new knowledge. For this reason, despite the controversy over the legitimacy of protecting biotechnological inventions, an effective source of its acquisition may be patent systems that provide a rich, substantively verified database of the latest developments.

The aim of the paper is to assess the importance of patent systems for the process of knowledge diffusion in the field of biotechnology. For its implementation, research has been carried out to answer the extent to which Polish biotechnology companies derive patent systems as sources of knowledge used in the creation of new inventions. The research method used for the purposes of the article is a method of analysis of two-part patent citation, references to other inventions and references to the subject literature. As the source material, technical documentation (description) of inventions for which patent protection was granted was used. The research did not cover patent applications, which would significantly extend the available sample, because in this case, the technical documentation has not been made available. The subjective scope of research covered 40 Polish biotechnologically active enterprises in the last 28 years (between the date of the oldest and the newest granted patent). The resources of the Polish patent system and, for the purposes of verification and supplementation, the ESPACENET database were used to obtain the necessary documentation.

\section{Diffusion of knowledge in the field of biotechnology}

Diffusion of knowledge means the process of its dissemination leading to the creation of new knowledge. Past achievements become an inspiration to create completely new solutions. The diffusion process is not only about the acquisition of knowledge and technology, because thanks to them companies are constantly learning and are based on them in further activities. The diffusion of new knowledge and technology has become an essential element of the innovation process, primarily in industries focused on the creation and commercialization of inventions. Diversified theories of knowledge diffusion and its impact on the innovation process [2-4] in a different way interpret factors influencing the decisions of enterprises about the introduction of new technologies, conditioning access to knowledge and the ability to absorb it. These include dynamics of international circulation of scientific knowledge made available through magazines, conferences or seminars, mobility of employees and scientists (first and foremost, exchange of doctoral students), concluding licensing agreements, including non-exclusive ones, technical solutions made available as part of opening the innovation process, the so-called centers of excellence, engaged in conducting research, implementation of research projects and programs, and conducting educational activities, service and training, transfer of knowledge from university to industry, network connections, e.g. clusters or technology parks, which, thanks to their collective character, stimulate the exchange of knowledge, mutual learning and innovation $[5,6]$. Part of the technical knowledge has been systematized in scientific studies, created technical standards, and procedures, in this case, the decisive factor is the ability to reach and creatively process the knowledge contained in them. Examples of resources of such codified knowledge are patent systems with diversified geographical coverage. In turn in relation to the so-called classified knowledge and knowledge resulting from routine methods of conduct, the most important thing is the degree of connections (direct interaction) between the company and external entities [7]. Identification and then stimulation of factors conducive to the diffusion of knowledge, especially technical knowledge, is a very problematic issue from the perspective of knowledge economies, 
among others for the reason that "knowledge resources in the enterprise are unique in relation to the place of knowledge accumulation and are difficult to transfer beyond the given enterprise. They remain its individual resource, which is not transferable outside the organization. So you can only capture some of the innovators' knowledge resources " [8, p. 4]. In addition, even in the case of knowledge made available to the public through specific media or transferred as part of the opening of innovation processes, finding it often involves significant costs, which is a serious financial challenge, often wasting the effort of inventing. For this reason, it seems that it is extremely important to create specific institutional incentives, thanks to which the diffusion of knowledge will move beyond the walls of the parent entity, improving the efficiency of communication between individual entities and creating new channels of information transfer, especially in the field of current technical and technological achievements. The abovementioned factors affect the diffusion of knowledge also in the biotechnology sector. It is recognized that the process of dissemination and diffusion of knowledge in this area is significantly influenced by the creation of biotechnology clusters [9] and the functioning of various types of knowledge networks [6]. The so-called geographical proximity factor is also important. It above all significantly stimulates the creation of groundbreaking innovations (inventions) [10]. On the other hand, Z. Somnez, examining companies from the biopharmaceutical industry, noticed that a large part of knowledge flows due to strong mobility of the workforce, and particularly breakthrough inventions use technical knowledge of a regional character only when acquired in the network [11]. Research by G. Guri and M. Mariani showed that geographical proximity shows significant connections with the level of inventors' education - the higher education, the greater the use of external sources of knowledge and greater geographical diversification of its sources. He points to the important role of education in shaping openness and overcoming geographical barriers that intensify the diffusion of knowledge. C. Roesler and T. Broekel point out that institutions that condition the creation and flow of knowledge are universities operating within the network, implementing joint research and development projects financed from public funds [12]. What is more, they are strongly influencing the diffusion of knowledge, even when the cooperation between the university and industry is only informal [13]. However, although the diffusion of university knowledge is crucial to the process of biotechnological innovation, many entities are faced with a dilemma whether its disclosure will develop or, on the contrary, undermine the chance of pursuing commercial interests [14]. Research on a sample of over 40,000 patents from the semiconductor and biotechnology sector showed that solutions with an average saturation of scientific knowledge are most frequently cited, while the dynamics of diffusion of technical knowledge assumed the highest values in relation to patents containing the highest level of knowledge.

\section{Technical documentation of inventions as a tool for acquiring new knowledge}

As mentioned above, an important source used in the process of diffusion of technical knowledge in the field of biotechnology is the technical documentation of inventions, accumulated in patent systems. Patent databases are classified as external, open source, they do not require the purchase of technology or intellectual property rights, nor are they directly interacting with the source, so they do not generate costs due to their use. Patent documentation is divided into two groups: applications for protection for a given solution and granted patents, together with search reports, modifications and translations introduced in the documentation. The patent document contains basic information - the title of the invention, data of the inventor or authorized entities, a detailed description of the invention containing data on the application of the invention, its construction together with 
a technical drawing, the scale of originality and the benefits that will potentially result from its use, the scope of protection requested / granted and references to other substitute or complementary technical solutions to a given problem. The special role of patent knowledge stems from the fact that patent databases also contain other documents shared with technical significance for the procedure of granting an exclusive right, as it illustrates the general or specific state of the art. Among them there are articles from scientific journals, conference reports (including abstracts), books, internet publications, specialist or industry blogs, websites of innovatively active entities. In addition, the resources of patent systems also contain information that has not been codified elsewhere. To analyze the process of diffusion of technical knowledge accumulated in patent resources, methods based on patentometry are used. They are widely used and have been provided with extensive literature studies [15]. Two patentometry methods are used, analysis of patent citations and analysis of references to the state of the art. The first one is divided into two basic types - quoting literature and quoting other patents. Quoting of literature allows tracking the directions and intensity of the flow of specialist knowledge, mainly scientific, from researchers to inventive active entities. The patent citation research focuses on the examination of quotations of patents granted so far and patent applications placed in the document submitted for protection of the invention, which allows to assess the impact of technical knowledge embedded in previous inventions on creating completely new solutions. The second method - the analysis of the state of the art, constitutes an objective assessment of the state of the art, allows to verify the breakthrough of the proposed solution with reference to previously known inventions. For the needs of the paper, the first of the described methods was used, i.e. citation analysis. The citation method has a long tradition, starting with research by Grilichesa, Trajtenberga, Jaffe, Hendersona and Cabello [16]. Patent citations play a significant role in the general equilibrium model of Caballero and Jaffe, whose citation function is a function that grows to diffusion and decreases to the aging of technical solutions. In this model, the diffusion of knowledge occurs as a compilation of the probability of finding an earlier invention, its usefulness in creating a new and aging degree of the earlier invention [17, p. 262-263]. The patent citation method allows to evaluate the meaning of inventions from the perspective of benefits achieved by a given community. Studies conducted by Trajtenberg have shown that the more citations of a given invention, the greater the social gains from its commercialization. The patent statistics have also been applied in the studies conducted by Schmookler analyzing the interdependence of inventive activity with economic growth (previously similar studies have led, among others Kalador, Cornwall or Dixon and Thirlwall) [17, p. 260]. The patent citation method was also used by Sjöholm, who, looking for a correlation between quotations of foreign patents and bilateral import directions, confirmed the importance of import in the diffusion of technology [17, p. 272]. Patent citation also formed the basis for the macroeconomic concept of economic growth linked to empirical data of a microeconomic nature, developed by Caballero and Jaffe [17, p. 262].

\section{Diffusion of biotechnology knowledge on the example of selected enterprises}

In the research conducted for the needs of the publication, the inventive activity of 40 Polish enterprises from the biotechnology industry, considered as enterprises focused on introducing product and process innovations, was analyzed. However, further verification, based on patent applications and patents granted, showed that only 18 of them have achievements in the field of the most economically desirable breakthrough innovations, that is inventions. The time range of the research was relatively wide, covering the years 1989-2017. Due to generally low inventive activity of Polish enterprises was 
analyzed the technical documentation of all solutions for which exclusive rights (patents) were granted. During this period, the selected companies received a total of 88 patents, the largest number of which was received by Adamed (in total, in the years 1987-2013, as many as 33 patents). The qualitative analysis of descriptions of inventions, which is an obligatory part of the technical documentation, showed that there were a total of 669 citations to literature and other patents. A characteristic feature of citations is their high degree of internationalization - as many as 605 citations referred to foreign sources, only 64 to sources of national knowledge (Fig. 1). This indicates the aforementioned dependence of the developed inventions on the geographical factor, in the sense that the more breakthrough the solution, the more strongly diversified sources of external knowledge are used.

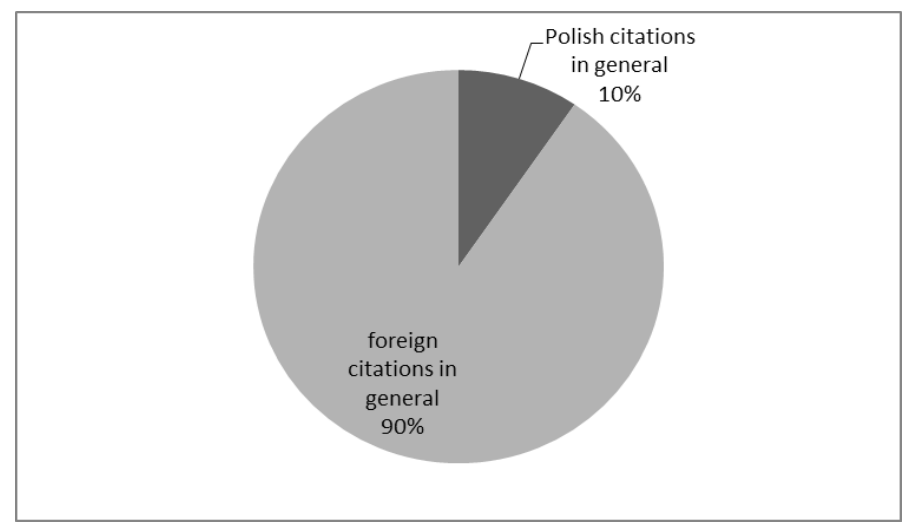

Fig. 1. Share of foreign and Polish citations in the total number of citations. Own elaboration based on the Polish Patent Office and Espacenet data.

Regardless of the geographical origin of the sources of technical knowledge used, the technical documentation of patents plays the dominant role. While the quotations of literature, respectively Polish and foreign, accounted for a total of $36 \%$, the number of references to patents was almost twice as much - 64\% (Fig. 2).

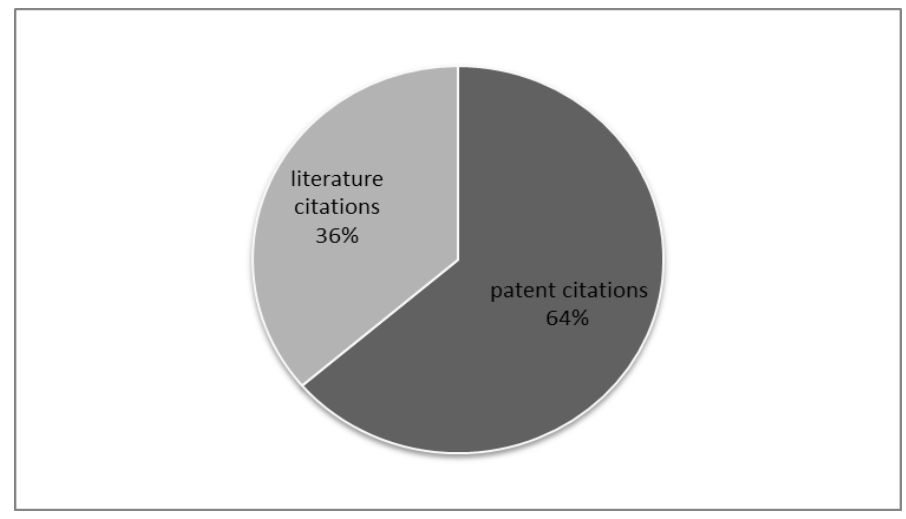

Fig. 2. Share of patent and literature citation in the total number of citations. Own elaboration based on the Polish Patent Office and Espacenet data.

Quoting of Polish literature or referring to the publications of Polish authors is not a frequent phenomenon, in the analyzed documentation it appeared only 21 times. Twice 
more often referred to the technical documentation of domestic inventions - citations of this type appeared 43 times. In this case, the documentation resources of the Polish Patent Office were used as the source of information. The results of the analysis of references to foreign sources were different. In this case, patent systems also contained Polish inventions, which the applicants decided to protect by way of a non-national but international protection procedure. Due to purpose of the paper - identification and evaluation of diffusion of technical knowledge - they were assigned to individual patent resources without unnecessary national identification here. In this context, references to foreign literature accounted for $37 \%$ of the total number of citations. Qualitative analysis allowed for the geographical identification of the scientific studies and reports used (Figure 3).

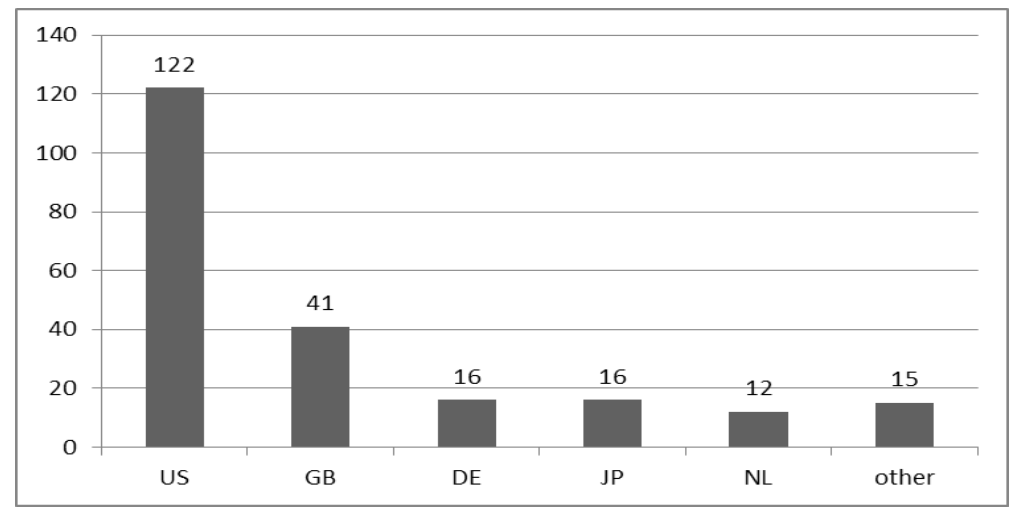

Fig. 3. Geographical identification of literature sources. Own elaboration based on the Polish Patent Office and Espacenet data.

The dominant role in the process of diffusion of knowledge through literature publications was played by American publications. References to them were more frequent than the sum of citations to the source literature of all other countries. References to the United Kingdom literature - the second in terms of frequency - accounted for one-third of citations in American literature. The same number of citations was noted when referring to German and Japanese publications. However, the technical descriptions of patents in individual, foreign patent resources were by far the largest factor in the diffusion of technical knowledge. They constituted as much as $63 \%$ of the total number of references to international sources, which clearly indicates the importance of patent citations in the process of diffusion of technical knowledge (Fig. 4).

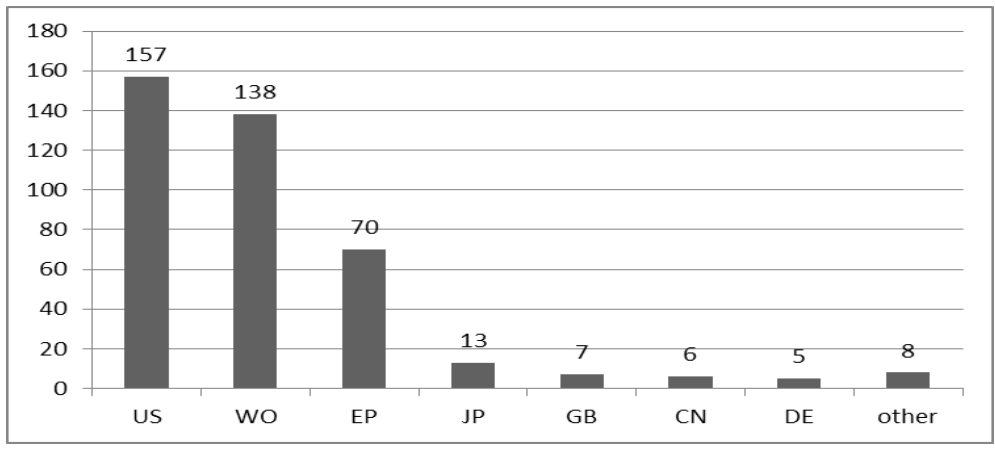

Fig. 4. Geographical identification of patent systems constituting the source of cited patents. Own elaboration based on the Polish Patent Office and Espacenet data. 
Also here, the leading role was played by references to technical knowledge contained in the solutions made available by the US patent system. However, learning from the second most frequently quoted patent system - World Intellectual Property Organization (WIPO) - was almost as intense. The difference between references to these two patent systems was only 19 citations. Surprisingly, Polish biotechnology companies relatively seldom used knowledge available via the European Patent Office in comparison to the two leading systems. In this case, only 70 citations were recorded. EPO citations were, accordingly, $31 \%$ of the citations of patents from the US system and $34 \%$ of citations from WIPO resources. A few citations referred to solutions provided by the Japanese, British, Chinese and German patent systems. Individual references concerned inventions found in the resources of regional systems: Ukrainian (4), Brazilian (2), French (2). If citation of patents from the base of the patent system of the Republic of Poland should be placed on the above list, these references would be ranked 3rd in terms of frequency of citations (43 references).

\section{Summary}

Visible in the literature on the subject, in jurisprudence and economic practice disputes over the legitimacy of patenting biotechnological inventions, show that this area requires determined actions aimed at understanding mutual relationships between intellectual property rights and the effectiveness of technology transfer, protection and sustainable use of biodiversity and non-discriminatory distribution of benefits obtained from genetic resources, including the protection of extremely specialized knowledge [1]. However, the inclusion of biotechnological inventions in a network of institutionally protected solutions opens the potential to intensify the process of diffusion of knowledge, especially valuable knowledge, and, it happens, that nowhere else is shared. This trend, the verification of the role of modern patent systems is characteristic not only for biotechnological inventions. In this sense, the patent is not a blocking of the innovation process but a guarantee of further penetration of knowledge into new, previously undeveloped areas. The research conducted for the needs of this paper showed that for Polish biotechnology companies, patent systems are an important source of knowledge - they use not only ready-made solutions, but also literature knowledge in this regard. Characteristically, in their case the knowledge diffusion process shows a very high degree of internationalization, based primarily on the resources of foreign patent systems. Issues of geographic proximity do not matter in this case, which is confirmed by the results of research indicating a negligible importance of this factor in the case of breakthrough innovations. The national patent system, if it is used, is the source of knowledge derived from ready inventions, and to a small extent as a base of literature knowledge. Concentration on foreign sources of knowledge is a clue as to the direction and development potential of Polish enterprises, which become full participants of the global market, but mainly focused on the US biotechnology sector.

\section{References}

1. Dyrektywa Parlamentu Europejskiego i Rady 98/44/WE z dnia 6 lipca 1998 r. w sprawie ochrony prawnej wynalazków biotechnologicznych (Dz.U. L 213, 1998) $13-21$

2. B.H. Hall, The Oxford handbook of Innovation (Oxford University Press 459-484, 2004)

3. B.A. Lundvall, National Systems of Innovation: Towards a Theory of Innovation and Interactive Learning (Anthem Press, 2010) 
4. R.R. Nelson, National Innovation Systems: A Comparative Analysis (Oxford University Press, 1993)

5. R.M. Grant, C. Baden-Fuller, Journal of Management Studies 41, 1 (2004)

6. M. Mueller, K. Bogner, T. Buchmann, M. Kudic, J. Econ. Interact. Coor. 12, 3 613-634 (2016)

7. R.R. Nelson, S.G. Winter, An Evolutionary Theory of Economic Change (Harvard University Press, 1982)

8. A. Wziątek-Kubiak, Polska transformacja po latach (C.H. Beck, 2009)

9. D.K.N. Johnson, M. Mareva, Colorado College Working Paper, 01 (2002)

10. A.B. Jaffe, M. Trajtenberg, R. Henderson, Quarterly Journal of Economics 108, 3, 577-598 (1993)

11. Z. Sonmez, Sci. Publ. Policy 44, 5 (2017)

12. C. Roesler, T. Broekel, Review of Regional Research 37, 135-160 (2017)

13. N. Fukugawa, Asian J. Technol. Inno. 24, 100-120 (2016)

14. A .J. Nelson, Organisation Science 27, 2, 265-285 (2016)

15. M.H. Fallah, E. Fishman, R.R. Reilly, Proceedings of Portland International Conference on Management of Engineering \& Technology 1-5, 420-427 (2009)

16. M. Niklewicz-Pijaczyńska, Studia Ekonomiczne 214, 242-252 (2015)

17. S. Kubielas, Innowacje i luka technologiczna $w$ gospodarce globalnej opartej na wiedzy. Strukturalne i makroekonomiczne uwarunkowania (WUW, 2009) 